\title{
Representaciones, efervescencia colectiva y reproducción social. Trazos para un debate en clave contemporánea
}

\author{
Representations, collective effervescence and social \\ reproduction. Traces for a contemporary debate
}

\author{
Ana Lucía Grondona \\ UBA \\ antrondona@hotmail.com
}

Recibido: 30.01 .2012

Aprobado definitivamente: 17.04.2012

\begin{abstract}
RESUMEN
El artículo propone una reflexión alrededor de algunos conceptos clave de Las formas elementales de la vida religiosa (ritual, efervescencia colectiva, creencia) en vistas a construir un diálogo con autores contemporáneos (Louis Althusser, Ernesto Laclau, Judith Butler) que han reflexionado sobre el papel de los imaginarios en la producción y reproducción de la sociedad. El trabajo está organizado en tres apartados. En el primero indagamos en la noción de "efervescencia colectiva", que resulta nodal para comprender el proceso mediante el cual las sociedades a la vez que se representan se fundan. En el segundo, analizamos la productividad de esa efervescencia colectiva en términos de signos, ordenes imaginarios y comunidades de creencias. En el tercero, analizamos las ambivalencias de la producción y reproducción de ese orden imaginario, atendiendo, por un lado, a su constitutiva precariedad (y contingencia) y, por el otro, a las paradojas propias de la reproducción de las comunidades de creencias bajo el signo de la pluralidad y del individualismo moral de la modernidad. Finalmente, propondremos algunas reflexiones a partir del recorrido del texto y de las preguntas que lo originaron.
\end{abstract}

Palabras Clave: Efervescencia colectiva, ritual- representaciones, performatividad, comunidad de creencias, ambivalencia.

\begin{abstract}
The article proposes a reflection on some key concepts of The Elementary Forms of Religious Life (ritual, collective effervescence, belief) in order to build a dialogue with contemporary writers (Louis Althusser, Ernesto Laclau, Judith Butler) who have reflected on the role of imaginaries in the production and reproduction of society. The paper is organized into three sections. In the first one, we explore the notion of "collective effervescence", vital to understand the process by which societies represent and found themselves. In the second section, we discuss the productivity of collective effervescence regarding the creation of signs, imaginaries and communities of belief. In the third section, we analyze the ambivalence in the production and reproduction of imaginary orders, both regarding their constitutive contingence and the specific paradoxes of belief communities under the sign of modern pluralism and individual difference. Finally, we will propose some concluding remarks.
\end{abstract}

KeYwords: Collective effervescence, ritual, representations, performativity, community of beliefs, ambivalence. 


\section{SUMARIO}

1. El polisémico concepto de "efervescencia colectiva". 2. La productividad de la "efervescencia colectiva": acción colectiva y reproducción social. 3. El puro exceso: inestabilidad y ambivalencia. 4. Reflexiones finales... A propósito de Durkheim y el Sur. 
En el presente trabajo ${ }^{1}$, partimos del texto de Las formas elementales de la vida religiosa (Durkheim, (2007) [1912]; en adelante $F E$ ) para delinear los contornos de un diálogo posible entre Émile Durkheim y autores que más contemporáneamente han reflexionado sobre el problema de la reproducción social, particularmente alrededor de la noción de "Ideología" (vgr. Louis Althusser, Ernesto Laclau y Judith Butler). La invitación a este diálogo puede resultar quizás algo polémica. Por una parte, podría justificarse esta apuesta apelando a la de-construcción foucaultiana de la noción de "autor", que nos habilita a proponer articulaciones aún allí donde los individuos de "carne y hueso" habrían puesto serios reparos. El que imaginemos "al hombre" Émile Durkheim asistiendo incómodo al diálogo que aquí proponemos no es obstáculo para insistir en él. Esta invitación, sin embargo, tampoco se presenta como arbitraria. La hipótesis respecto de que algunos de los planteamientos de $F E$ "anticipan" problemas de la teoría althusseriana (y de sus derroteros) no resulta descabellada si se atiende a la relación entre la sociología durkheimiana, el estructuralismo y el post-estructuralismo. Ahora bien, la construcción de esa genealogía no es el objetivo de este trabajo, aunque tengamos sobre ella algunas intuiciones. El texto que aquí presentamos tiene la más modesta pretensión de ofrecer unas "claves de lectura" que permitirían pensar un ámbito de problemáticas compartidas.

En términos del campo de análisis y estudios sobre la "obra" de Durkheim, este trabajo cuenta con antecedentes relevantes, como el de Kenneth Thompson (1998), interesado en la intertextualidad entre Althusser y el sociólogo francés. Del mismo modo, en publicaciones recientes, Jeffrey Alexander (2011) se muestra dispuesto a servirse de las reflexiones de Judith Butler para un análisis sociológico de la "dimensión performativa" del poder, en el que también ocupa un lugar relevante el estudio de $F E^{2}$.

En el recorrido del texto, intentaremos dar cuenta de la "actualidad" teórico-política del texto de $F E$, aun cuando Durkheim parezca abandonar alli ${ }^{3}$ los contextos modernos a los que sus análisis nos habían acostumbrado, para dedicarse a un estudio de lo "originario" o, al menos de lo "elemental". Por más de cuatrocientas páginas, se nos detallan los sistemas de creencias y prácticas de sociedades "primitivas" que habían fascinado a la antropología. A pesar de ello, el texto interroga sobre el mundo contemporáneo (de Durkheim, pero también del nuestro) y el estatuto del lazo social en él.

Puntualmente, en la pregunta respecto de la productividad de prácticas y representaciones religiosas se avizora cierta nostalgia, resultado de un tiempo de "transición y mediocridad moral" (FE: 397), que se lamenta por la letanía de dioses que no terminan de morir y, sobre todo, por los que no terminan de nacer. Ahora bien, ¿frente a qué pasado de mitos y ritos se presentaba, ese comienzo del siglo XX ( $\mathrm{X}$ del siglo XXI?), como una época pálida e incapaz de suscitar entusiasmos? ¿Serían los Arunta el espejo en el que el individuo del industrialismo capitalista debía mirarse afligido y duelar los dioses en los que ya no creía? Pero, ¿había creído alguna vez en esos dioses y sus poderes? Difícilmente. En un muy citado pasaje, Durkheim nos recuerda otras deidades, más cercanas, que nos interpelan (ellas sí) en nuestro carácter de individuos modernos:

La sociedad para erigirse en un dios o para crear dioses no fue en ningún momento más perceptible que durante los primeros años de la Revolución Francesa. En aquel momento (...) cosas puramente laicas fueron transformadas (...) en cosas sagradas: así la Patria, la Libertad y la $R a-$ zón (...) en un caso determinado se ha visto que la sociedad y sus ideas se convertían directamen-

\footnotetext{
${ }^{1}$ Agradezco las sugerencias y comentarios de Pablo Nocera a una primera versión de este artículo y el impulso del equipo de investigación de "Sociologías de la comunidad" dirigido por Pablo de Marinis para trabajar en algunas de las líneas que aquí se presentan.

${ }^{2}$ Aunque se sirve de muchas de sus reflexiones, Alexander también establece diferencias con el abordaje butleriano, y aún más con el althusseriano. El presente trabajo sigue otra línea de indagación que, aunque se emparenta en algunos puntos, parte de otras preguntas

${ }^{3}$ Este "abandono" de los contextos modernos por los originarios tenía antecedentes en los trabajos del sociólogo francés, vgr. en Sobre algunas formas primitivas de clasificación en co-autoría con Marcel Mauss, de 1902
} 
te, y sin transfiguración de ningún tipo, en objeto de un verdadero culto ( $F E$ : 201, énfasis nuestro).

En este pasaje se trasluce una preocupación política que, junto con otras, alberga el texto de $F E$. En el presente artículo nos interesará trabajar particularmente sobre esta veta, pues a partir de ella es posible hacer de Durkheim un contemporáneo de los debates en torno de la producción y reproducción de la dimensión imaginaria de la sociedad, como problema a la vez sociológico y político.

Entendemos que el ejercicio propuesto resulta pertinente no sólo en sí mismo, como primer ensayo de genealogías más o menos inverosímiles, sino sobre todo en virtud de la emergencia de fenómenos sociales frente a los que cierta sociología celebratoriamente posmoderna pareciera permanecer muda. Concretamente, la evidencia del fin de los grandes relatos, la crisis de las representaciones totalizantes, la improbabilidad de nuevos panteones laicos pareciera primar en cierto sentido común sociológico abocado, a partir de ello, a la descripción de las pequeñas interacciones cotidianas. Términos como "Estado-nación", "clase" o "pueblo", parecieran perimidos en algunos abordajes, según los cuales la promesa del desencantamiento del mundo estaría plenamente cumplida.

En este contexto general, pero más particularmente en el que sirve de superficie de emergencia de este trabajo (el Sur), resultan refrescantes las sentencias de un sociólogo decimonónico que afirmaba que una sociedad es ante todo, la idea que se hace de ella misma. Ello no como un acto subrrogatorio del que pudiera prescindir, sino como un movimiento que la funda ( $F E:$ 392). Estos enunciados nos obligan, pues, a poner en duda la evidencia de una posmodernidad sin mitos, y a preguntarnos por los que, inadvertidamente, han conformado la relación que nuestras sociedades mantienen con ellas mismas. También, nos habilita a reflexionar sobre la emergencia de los relatos y representaciones que recientemente han devenido centrales para performar otras identidades colectivas en nuestras latitudes (aquí, el ejemplo más a mano es el de "los pueblos originarios"); y nos permite hacerlo a resguardo de desgastados diagnósticos sobre el "atraso" que ello supondría respecto de ciertas formas (supuestamente) más "puras" de la "modernidad". Sobre ello volveremos en las conclusiones.
El recorrido del presente texto está organizado en tres apartados. En el primero, tomamos la noción de "efervescencia colectiva", que resulta central para comprender el proceso mediante el cual las sociedades se representan y se fundan. En el segundo apartado, analizamos la productividad de esa efervescencia colectiva en términos de signos, ordenes imaginarios y comunidades de creencias. En el tercero, nos interesará indagar en las ambivalencias de la producción y reproducción de ese orden imaginario, atendiendo, por un lado, a su constitutiva precariedad (y contingencia) y, por el otro, a las paradojas propias de la reproducción de las comunidades de creencias bajo el signo de la pluralidad y del individualismo moral de la modernidad.

A partir del segundo apartado, articularemos el hilo argumental que esbozamos en el párrafo anterior en un diálogo con algunas reflexiones de Louis Althusser, Judith Butler y Ernesto Laclau alrededor del problema de producción de la sociedad como una (imposible) totalidad plena de sentido. Finalmente, propondremos algunas reflexiones a partir del recorrido del texto y de las preguntas que lo originaron.

\section{EL POLISÉMICO CONCEPTO DE "EFERVESCENCIA COLECTIVA"}

Tal como se trasluce en el pasaje citado más arriba, Durkheim no disimula su añoranza por los "períodos históricos en los que, bajo la influencia de algún gran descalabro colectivo, las interacciones sociales se hacen mucho más frecuentes y activas", en lo que aparece como "una efervescencia general, característica de épocas revolucionarias o creativas" (FE: 198). Resulta curiosa esta última sinonimia (revolucionarias-creativas), para quien había sido mucho más cauteloso respecto de las revoluciones y había denostado abiertamente la efervescencia colectiva como "enfermiza". La revaloración de estos momentos creativos no lo inhibe de dar cuenta de sus contradicciones. Por el contrario, Durkheim reconoce que en tales momentos extraordinarios, las pasiones que nos agitan son tan intensas que impulsan a actos violentos y desmesurados, "de heroísmo sobrehumano o de barbarie sanguinaria" (FE: 198).

Según ha desarrollado Pablo Nocera (2009) en un minucioso trabajo de sistematización, el de "efervescencia colectiva" es un concepto singularmente 
polisémico en la obra de Durkheim. Así, se distinguen tres aproximaciones diversas: En un comienzo, el sociólogo francés habría asimilado este problema al de las muchedumbres, asignándole además connotaciones fuertemente negativas que la inscribían en el terreno de la anomia, uno de los males contemporáneos que desvelaba a nuestro autor. De allí que en La Educación Moral, pero sobre todo en El Suicidio, se refiera a una "efervescencia enfermiza", asociada a la concupiscencia, a imágenes calenturientas, goces oscuros y sensaciones sin nombre (Nocera, 2009: 100).

Aun manteniendo estas adjetivaciones negativas, en lo que Nocera identifica como segunda aproximación, Durkheim habría de conceptualizar el fenómeno de un modo más ambivalente, subrayando la inestabilidad de estos estados, pero también su profunda creatividad. Así en textos como Educación y Sociología o en el ya citado El Suicidio, Durkheim no descartaba la productividad moral de aquello que en principio parecería sólo una extraordinaria desorganización de cuerpos y signos.

A partir de 1900, sostiene Nocera, y a medida que el fenómeno religioso adquiere centralidad y complejidad como objeto privilegiado de las preocupaciones durkheimianas, la efervescencia colectiva pasaría al centro de las indagaciones. Particularmente, en $F E$ se insiste en el carácter productivo y moral de estas reuniones extraordinarias en las que se exaltan las pasiones. En este sentido, el fenómeno que en principio parecía asociado con la disrupción del orden, adquiere un carácter fuertemente integrador, aún cuando ello vaya en desmedro de la regulación. En efecto, se trata de momentos en que se suspenden las normas y los códigos, produciéndose prácticas que las exceden, pero que - en virtud de esta misma suspensión- no caen bajo la forma del crimen. Estas congregaciones habitadas por cierta "electrificación", "agitación" y "magnetismo" producen imágenes y sensaciones que no se inscriben en el sistema de signos ni en la lógica que procura las certidumbres de la vida profana (Nocera, 2009: 97). Este hecho implica diversas consecuencias, por una parte la suspensión de las jerarquías, especialidades y temporalidades que regulan la vida cotidia- na, y, por otra, la emergencia de lenguajes no verbales, afectivos y móviles producidos por la comunidad efervescente (aspecto sobre el que volveremos en el apartado que sigue).

Pues bien, será justamente en su carácter integrador que a Durkheim le interesará analizar este fenómeno. Así, en $F E$ estudiará el modo en que estas corrientes eléctricas se articulan en las prácticas rituales de la vida religiosa. Este punto merece algunas aclaraciones, pues la noción de efervescencia excede a la de ritual. Ya desde Las reglas del método sociológico, nuestro autor está interesado por las "explosiones pasajeras" (Durkheim, 1965 [1895]: 25), que incluirá como objeto de la sociología. Ahora bien, éstas sólo requieren de los individuos reunidos en masa (réunis en foule). Los ritos religiosos, por su parte, son un tipo de reunión particular, pues suponen ciertas reglas respecto de cómo actuar frente a lo sagrado. El rito es una práctica regulada ${ }^{4}$. En este sentido, no son un momento de "pura explosión", o, mejor, ésta resulta en alguna medida contenida. Entendemos que la ambigüedad de los ritos religiosos como instancias normadas, pero siempre excedidas por la efervescencia (cuestión sobre la que también nos detendremos más abajo), explica buena parte del interés de nuestro autor por ellas.

En lo que hace a la caracterización y comprensión de los ritos religiosos, Durkheim adscribe a la perspectiva de Robertson Smith en diversos aspectos. Por un lado, adjudica centralidad a las prácticas religiosas, en particular a la ceremonia del sacrificio comunitario como núcleo ritual. En el banquete entre dioses y hombres, el tótem sacrificado funcionaba como mediador y propiciador de una perfecta fusión del grupo con su dios. En este ceremonial de comunión el clan resultaba el verdadero sujeto y objeto de la religión, y el tótem su representación (Ramos Torre, 2007: XIV). Ahora bien, Durkheim también pondera el papel de la ofrenda en estas prácticas, aunque en un sentido diverso al que James Frazer utilizaba para polemizar con Smith, pues el sociólogo francés descarta de plano una lectura utilitarista del ritual:

Hay que dejar pues de creer con Smith que el culto ha sido exclusivamente establecido en

\footnotetext{
${ }^{4}$ Ramos Torre (2010) distingue al interior de la reflexión de $F E$ rituales de demarcación, de purificación, conmemorativos, de oblación, de comunión, miméticos, lúdico estéticos, de duelo y, por último, de expiación
} 
beneficio de los hombres y que los dioses nada reciben: éstos lo necesitan tanto como los fieles. Sin duda, los hombres no podrían vivir sin los dioses. Pero, por otro lado, los dioses morirían si no se les rindiera culto.(...) No son ciertamente las oblaciones materiales las que, por ellas mismas, producen tal recreación, son los estados mentales que tales manipulaciones, en sí mismas vanas, suscitan o acompañan (...) Es preciso establecer que el rito tiene realmente por efecto de la recreación periódica de un ser moral del que dependemos tanto como él depende de nosotros. Pues bien, tal ser existe: es la sociedad. En efecto, por poca importancia que tengan las ceremonias religiosas, ponen en acción a la colectividad; los grupos se reúnen para celebrarlas. Su efecto inmediato es, pues, aproximar a los individuos, multiplicar entre ellos los contactos y hacer que sean más íntimos ( $F E$ : 320 ss, énfasis nuestro).

De este modo, los ritos actúan por su carácter extracotidiano, como irrupciones que suspenden la lógica del tiempo profano. Esta reunión de contactos íntimos producirá el doble efecto de moralizar a los individuos y reproducir la sociedad, en la medida en que se trata de un momento excepcional de experimentación de la fuerza colectiva que, justamente, la restituye en cuanto tal. En lo que sigue, analizaremos las consecuencias que estos procesos tienen a la hora de concebir las condiciones de la reproducción social.

\section{LA PRODUCTIVIDAD DE LA "EFERVESCENCIA COLECTIVA": ACCIÓN COLECTIVA Y REPRODUCCIÓN SOCIAL}

Tal como hemos señalado, la importancia otorgada por Durkheim a las instancias de reunión como ámbitos de integración social ("efervescencia colectiva") es una de las diferencias centrales entre la propuesta teórica de $F E$ y la del sociólogo de comienzos de la década del noventa del siglo XIX .Este último parecía más aferrado al vocabulario normativo de la regulación, quizás con la ilusión de fomentar la sumisión ciudadana y la integración social de precaria Tercera República. El sociólogo ya maduro, por el contrario, se muestra más preocupado por encontrar un lenguaje capaz de asir la producción de ideales trascendentes (Jones, 2005: 95).

En sintonía con ello, tenemos una primera perspectiva analítica del fenómeno religioso, centrada en la noción de tabú y signada por cierto formalismo y normativismo en la definición del fenómeno religioso (Lukes, 1984; Ramos Torre, 2007). Luego, emergería una posterior redefinición de lo sagrado en la que adquiere mayor relevancia el "culto positivo", en desmedro de la que había otorgado a la noción de "prohibición". En 1912, Émile Durkheim subrayaría el carácter productivo del fenómeno religioso. Esta productividad estaba vinculada, por ejemplo, al hecho de que las religiones elementales habrían organizado la percepción, haciendo posible, ni más ni menos que la experiencia del mundo.

Ahora bien, fundamentalmente, además de permitir comprender, las creencias religiosas impulsarían a la acción; y en ese sentido, también resultan "productivas" en sus efectos prácticos, ya no sólo teóricos: Quien tiene fe está obligado a actuar.

En tanto indagación sobre los modos en que el fenómeno religioso se vincula con la acción colectiva, el texto de FE vuelve a destilar una preocupación política. Por cierto, en este punto resulta posible establecer un ámbito de encuentro con reflexiones posteriores, provenientes del marxismo de entreguerras (Antonio Gramsci, George Sorel ${ }^{5}$ y Carlos Mariátegui ${ }^{6}$ ), dispuestas a interpretar la acción colectiva a partir de la matriz del mito, en el terreno de lo que se delimitaría como el problema teórico y político de la "hegemonía".

Pues bien, intentaremos mostrar que el modo en que en el texto se formulan las condiciones de la "reproducción social" también remiten al campo semántico en el que se inscribe el problema de la ideología-hegemonía. En efecto, esa formulación conduce a problematizar las condiciones de reproducción

\footnotetext{
${ }^{5}$ Para una relación sobre la relación mito y política en los trabajos de Durkheim y Sorel, referimos a D.B Sazbón (2003) “Articulaciones entre ciencia y política. La reflexión sociológica francesa a fines del XIX: Durkheim y Sorel”. Tesis de Maestría. Buenos Aires: FLAC

${ }^{6}$ Sobre este punto, agradezco los comentarios enriquecedores de Martín Cortes
} 
en términos de "un orden imaginario", habitado por corrientes divergentes incapaces de reducirse a la unidad a partir de un saber superador.

Ese "orden imaginario" no actuaría como un velo del que es posible liberarse, sino como una mediación necesaria y constitutiva de la relación (social e individual) con "la realidad". En el texto de 1912 no sería tanto Dios quien muere (como trascendencia), sino la utopía de una relación transparente con el mundo y con la sociedad ${ }^{7}$.

\subsection{Creencia y comunidad}

Según afirma Anne Rawls "las creencias y los símbolos presuponen que las personas ya son capaces de pensar y actuar en términos comunes" (2001: 42 , traducción nuestra). En los párrafos a continuación, presentaremos algunos elementos para debatir esta afirmación, pues entendemos que uno de los argumentos centrales tanto en FE (así como en Pragmatismo y sociología) es que no se puede sentir ni pensar en común sin la mediación de símbolos (punto relevante en relación al debate que aquí proponemos). Este argumento se enlaza con otro que sostiene que no se puede creer ni pensar sino en común, lo que supone, una comunidad de creencias, cuya producción y re-producción depende de rituales.

Desde la perspectiva del análisis que Stedman Jones (1998) propone sobre el trabajo durkheimiano, la religión es una panoplia de ritos y cultos que no existen sin la creencia; no entendida como aquello en lo que se tiene fe (mitos, imágenes, etc.), sino como facultad de creer. Esta disposición constituiría ciertos objetos, nombres y símbolos como sagrados. Así, éstos no preexisten a la creencia, sino que son producidos por ella. Resultan sólo una cristalización posible de ese impulso (élan), que nos hace actuar y nos ayuda a vivir. Por su parte, para Paoletti (1998), la creencia es un acto de la vida cotidiana, premisa de todo conocimiento, voluntad o pasión. De este modo, la certeza es también una forma de creencia.

Ambos comentaristas refieren a la ascendencia que Renovier habría tenido en las reflexiones durkheimianas, siendo muestra de ello la relevancia que nuestro autor otorga a la pasión y la voluntad en relación al intelecto. Justamente en virtud de esta perspectiva, se hace necesario insistir en la distinción entre el componente representacional, especulativo y cognitivo de toda creencia de su aspecto más dinamogénico, vinculado a la fe como una fuerza que arrastra y obliga a actuar.

En las representaciones científicas ambas funciones (la cognitiva y la dinamogénica) se mantienen separadas, pues éstas deben ser verdaderas (en su contenido especulativo) para ser sostenidas. Por el contrario, en el caso de las representaciones sagradas la distinción entre ambas funciones no resulta tan nítida. Así, en las religiones primitivas las dos están presentes y se superponen sin divisiones claras, dado que las creencias son cosmologías, representaciones de la realidad del universo, a la vez que impulsores de ciertas formas de acción (Paoletti, 1998: 131). Pues bien, el impulso de la fe propio de la facultad de creer, como disposición (más allá de cuáles sean las creencias particulares), es de naturaleza eminentemente colectiva:

Se puede elaborar perfectamente una filosofía en el silencio de la medición interior, pero no una fe. Pues una fe es, ante todo, calor, vida, entusiasmo, exaltación de toda la actividad mental, desplazamiento del individuo por encima de sí mismo. Ahora bien, ¿cómo podría este último acrecentar las energías que posee sin salir de sí mismo? ¿Cómo podría trascenderse contando sólo con sus fuerzas? (...) El hombre que siente una fe verdadera experimenta la necesidad inaplazable de expandirla; por esto, sale de su aislamiento, se acerca a los otros, intenta convencerlos, y es el ardor de las convicciones que suscita lo que acaba por reafirmar las suyas

(FE: 396; énfasis nuestro)

De este modo, la $f e$ es quizás el elemento distintivo del fenómeno religioso, en tanto reúne a la vez las nociones de creencia, de práctica y de comunión (Iglesia) que resultan constitutivas en la definición

\footnotetext{
${ }^{7}$ En sintonía con este razonamiento, cabe recordar que los avatares de la reflexión, la centralidad y relativa independencia concedida a la esfera de las representaciones míticas, habían implicado una revisión de la relación entre ciencia y práctica, en la que la primera podrá arrogarse un papel mucho menos ambicioso que en los primeros trabajos durkheimianos. Ello supuso, como contrapartida, una revalorización de la autonomía de la política y de la especificidad de sus lenguajes
} 
durkheimiana. Ahora bien, un punto sumamente interesante del análisis del texto de $F E$ es que la comunidad de creencias no puede constituirse como tal sin la mediación de un signo que la re-presente: el nombre crea al clan $^{8}$. Así, ésta se produce y reproduce a partir de una urdimbre de "símbolos" que necesariamente median:

Por sí mismas, las conciencias individuales están cerradas entre sí; no pueden comunicarse si no es por medio de signos en los que resulten traducidos sus estados interiores. Para que la relación que entre ellas se establece pueda dar como resultado una comunión, es decir, una fusión de todos los sentimientos particulares en un sentimiento común, es preciso, pues, que los signos que las hacen manifiestas lleguen también a fundirse en una única y sola resultante. La aparición de esta resultante es la que advierte a los individuos de que están al unísono y es ella la que les hace tomar conciencia de su unidad moral. Es al lanzar un mismo grito, al pronunciar una misma palabra, al ejecutar un mismo gesto que concierne a un mismo objeto, cuando se sienten y ponen de acuerdo ( $F E$ : 216, énfasis nuestro).

A partir de estas premisas se pone en marcha el sugerente y complejo juego de representaciones de la religión totémica, según lo entiende la perspectiva durkheimiana. El maná, o principio totémico, supone una primera forma de re-presentación, pues se trata de un modo abstracto de figurarse la fuerza impersonal de la sociedad. Se observa aquí un primer nivel de desplazamiento (o de metáfora) en el que las fuerzas sociales aparecen hipostasiadas bajo una figuración abstracta, impersonal y universal. Se trata de lo que Durkheim denomina el "sentimiento que una sociedad tiene de sí misma" y que surge de su reunión y de su concentración ( $F E$ : 324, 392). Ahora bien, la condición de que este "sentimiento" sea "común" es su representación material, la emergencia de un "signo".

Pero ¿cuál es el estatuto de ese signo? Para responder este interrogante cabe recuperar algunos elementos de la problematización que propone Pablo Nocera (2009). Según analizamos más arriba, la con- gregación de quienes están juntos se transforma en una totalidad efervescente en la que se suspende el sistema de organización de signos. Aparece, entonces, el puro exceso, y con ello, los límites del código que en la vida profana posibilita la comunicación:

Nuestros conceptos jamás consiguen controlar nuestras sensaciones y traducirlas enteras en términos inteligibles. Toman una forma conceptual sólo a condición de perder lo que hay en ellas más concreto, lo que interpela a nuestro ser sensible y provoca nuestra acción: devienen algo muerto y cuajado. "No podemos pues comprender las cosas sin renunciar, en parte, a sentir su vitalidad, y no podemos sentirla sin renunciar a comprenderla". (Durkheim, 2001 [1914a]: 7) Los tiempos efervescentes abren una nueva forma de comunicación no codificada aún, sostenida en cuerpos y movimientos Sin embargo, la condición de que estos sentimientos sean compartidos es, precisamente, que resulten simbolizados. La fuerza impersonal y eléctrica que nace de la concentración podrá ser representada de diversos modos (un grito, un canto, un nombre). Todos ellos son soportes de expresión del mismo principio. Al respecto, dirá nuestro autor que “el hombre ha debido empezar a dibujar menos con la idea de trazar sobre la madera o sobre la piedra bellas formas que fascinaran a sus sentidos, que con la idea de traducir de forma material su pensamiento" (FE: 117).

De este modo, el nombre, emblema, el tótem o el miembro operan como "signos" que ocupan el lugar de la "cosa" (la sociedad ideal, como sentimiento de sí misma), razón por la cual serán tenidos por sagrados. Ellos serán los amados y temidos, como ejemplifica Durkheim con la bandera, un pedazo de tela capaz de hacer actuar e incluso de reclamar sacrificios (FE: 207).

Estas representaciones tendrán efectos materiales, producir una comunidad de creencia y sentimientos, justamente a partir de la unidad del signo. Sin esta mediación, como hemos visto, las consciencias permanecen cerradas sobre sí mismas, sin poder fundirse.

8 "Se puede decir, de manera general, que el clan es un grupo familiar en el que el parentesco resulta exclusivamente de la comunidad de nombre" (FE: 94, énfasis nuestro) 
Pareciéramos enfrentarnos aquí con una paradoja: la existencia del colectivo depende de un sentimiento coaligante, para lo cual debe haber un signo común; pero, al mismo tiempo, éste no haría sino representar el sentimiento de sociedad que, sin embargo, no puede preexistir. Pues bien, la manera de salvar esta aparente caída en abismo es preguntarnos por el modo en que opera la producción de estas representaciones que suponen, al tiempo que crean, la comunidad de creencias.

\subsection{Comunidad, signo y performance}

Echando mano de nociones propuestas por Louis Althusser (1988), y luego reformuladas por Judith Butler (1997), podemos postular que el acto de producir simbólica y metafóricamente la unidad en y a través del signo resulta performativo respecto de la comunidad de creencias (es decir, de la sociedad en una de sus dimensiones fundantes). El "reconocimiento" de la comunión de consciencias en y gracias al grito, al nombre, al emblema o al animal totémico supone, al mismo tiempo, un "desconocimiento" de esta misma constitución. Se borran así las huellas del proceso de producción imaginaria como tal, y se restituye el efecto resultante como dato, como siempre-ya-existiendo.

En este proceso de reconocimiento-desconocimiento la "producción" de "la sociedad" es, necesariamente, la de su dimensión imaginaria. De este modo, el grupo no se experimenta a sí mismo más que mediado por una representación de sí como unidad y, entendemos, como comunidad. Como veremos, esta dimensión del famoso par conceptual Gemeinschaft-Gesellschaft que propuso Ferdinand Tönnies (de Marinis, 2010), se muestra como un fantasma que, en su propia emergencia, confina a la "sociedad" a la melancolía por la pérdida de una totalidad originaria.

Para actuar y crear en común, la fiebre de la efervescencia produce "metáforas" que hacen que el grito, el gesto o el nombre resulten algo más que su pura materialidad concreta, que su "literalidad". Aunque estas representaciones desafíen la estabilidad del sistema de signos y señalen sus límites, su destino será el de cristalizar, pasada la fiebre, en un código (renovado) que las contenga. Toda forma de estabilización de sentido mediante estos códigos resulta precaria y contingente, pero justamente por ello, impulsará a nuevos y fallidos intentos de sutura capaces de dar cuenta de aquello que siempre los excede (Recordemos "no podemos pues comprender las cosas sin renunciar, en parte, a sentir su vitalidad, y no podemos sentirla sin renunciar a comprenderla" Durkheim, 2001 [1914a]: 7).

Según queda expuesto, la efervescencia en su faz performativa no parte de términos comunes, debe crearlos y, en este sentido, evidencia la precariedad de la producción de "lo social".

A este respecto, entendemos que es posible establecer nuevas vinculaciones con las posiciones derivadas de la crítica althusseriana a Marx. Según ésta, la Ideología no debería ser analizada como una "falsa consciencia" que "oculta" el mundo a los ojos, pues ello supondría una utopía de transparencia posible. Por el contrario, cabe definirla como las "relaciones imaginarias" que se establecen con las propias condiciones de vida. En sintonía con lo desarrollado por Lacan en el "Estadio del espejo" (Lacan, 2003), se entiende que la experiencia de sí (colectiva o individual, debiéramos precisar) supone siempre una mediación en la que funcionan imágenes que remiten a una "completud" ("identidad") que "rescata"/conforma al yo (nosotros) fuera de la pura fragmentación innombrable. Proponemos entender la "comunidad de creencias", y su materialización en diversos signos, como esa instancia de alienación en la que la proyección en una imagen "completa" y "plena" permite constituir un "nosotros" integrado, pero a condición de una existencia absolutamente precaria. La arbitrariedad del signo, así como la imposibilidad de fijar plenamente el exceso de sentido que emerge en cada nuevo episodio efervescente, son síntomas de esa precariedad. La sociedad no puede experimentarse a sí misma de modo inmediato. En efecto, según Durkheim, la religión es antes que nada un sistema de nociones por medio de las cuales los individuos se representan la sociedad y "las relaciones, oscuras pero íntimas, que sostienen con ella" ( $F E: 211$, énfasis nuestro).

Tal como hemos señalado al comienzo de este artículo, Kenneth Thompson (1998) representa un antecedente importante para nuestra línea de argumento, dado que también entiende que ciertas conceptualizaciones de Durkheim en $F E$ pueden ser puestas en diálogo con las althusserianas. Así, desde la perspectiva de Thompson ambos referirían a esta dimensión imaginaria como una instancia universal 
de la vida social. Esta universalidad se derivaría de su función de cohesión social, en tanto proporciona una representación mítica de la estructura social subyacente. Tanto para Durkheim como para Althusser, esta dimensión actúa de tal manera que permite reproducir el orden social, representándolo simbólicamente como una unidad en la que el sujeto individual tiene un lugar. Al mismo tiempo, los símbolos funcionan generando un sentido de identificación y de pertenencia. Así, el individuo sería interpelado o construido como sujeto dentro de un discurso simbólico, que, en el mismo movimiento, constituye las comunidades ideológicas imaginarias.

En sintonía con este planteamiento, Ernesto Laclau (1996 y junto con Chantal Mouffe, 1987) recupera la crítica althusseriana a la noción de "totalidad" hegeliana -que seguiría operando en Marx bajo la forma de la mera "inversión" de la contradicción simple. A partir de ello, este autor argentino, propone entender la práctica hegemónica como el intento siempre fallido, pero por ello incesante, de producir una sutura de sentido de "lo social", de significarla como totalidad racionalmente unificada. La práctica hegemónica, entonces, produciría efectos de sutura que, sin embargo, siempre fracasan, pues permanecen perpetuamente reabiertos a disputas. Esta dinámica implica, como condición, la formulación de antagonismos: Mediante la delimitación de fronteras de sentido se excluyen radicalmente ciertas identidades como alteridades (exteriores) y pueden producirse "metáforas" que intente asir la totalidad de un sistema de identidades interiores.

En este punto regresamos a una pregunta que desde el comienzo acecha a Durkheim: ¿cuál es el lugar del conflicto (no ya "antagonismo") en su teoría? Entendemos que puede sostenerse una lectura del "crimen" como un síntoma de alteridad mediante el cual la sociedad reacciona/se produce como un todo. En este sentido, podríamos entender que funciona como una suerte de metáfora de "lo otro" (lo absoluta e inconmensurablemente diverso), de la amenaza que impide la positividad plena de la sociedad, pero que precariamente, ayuda a constituirla a partir de un "efecto de frontera".

Al igual que para Ernesto Laclau, la totalización (siempre metafórica) está para Durkheim habitada por fisuras. En el caso de éste último, el crimen, el daltonismo moral (Durkheim, 2000: 70) y los ex- cesos de la efervescencia son muestras de lo que se resiste a ser contenido bajo codificaciones.

Entendemos que, a este respecto, también es posible incluir la noción de "abyección" que propone Judith Butler (1993) para las formas de vida y de deseo que quedan por fuera del campo de inteligibilidad que prescribe cierto código. Al igual que para Laclau, la posibilidad de constitución de identidades individuales o colectivas (incluida "la sociedad"), supone una forma de expulsión radical. Los cuerpos "anormales" (los que en el esquema de Durkheim identificaríamos como "criminales"), serán marginados y, mediante esta marginación, se reinscribirá (y reproducirá) la norma. Ésta se estabilizará precariamente en la exclusión de aquello que no puede contener y en su repetición ritual. A partir de lo cual, garantizará ciertas formas de ser como posibles y un determinado orden social e imaginario; sin embargo, en virtud de que éste no es "necesario" ni tiene "fundamento", regresará siempre el problema del exceso.

\section{EL PURO EXCESO: INESTABILIDAD Y AMBIVALENCIA}

Reflexionaremos en este apartado sobre las condiciones de emergencia de los signos e imágenes que median en la relación de la sociedad con la "realidad" y, sobre todo, con ella misma. En particular, nos interesa analizar la inestabilidad y ambivalencia de estos signos. Para ello, el presente apartado se desdobla en dos secciones: Por una parte, abordaremos el problema de la arbitrariedad constitutiva de la relación de representación y las contingencias de su necesaria re-vivificación en rituales (primero en el planteo butleriano, para desde allí regresar al durkheimiano). Luego, trabajaremos sobre las ambivalencias propiamente modernas de estas formas de "lo común" en el marco de sociedades diferenciadas y plurales.

\subsection{La excepción y sus excesos}

En tanto los símbolos mediante los cuales un grupo se representa a sí mismo resultan siempre arbitrarios (¿por qué un canguro como tótem antes que un pelícano?) y fijados contingentemente, su estabilidad depende de la re-producción periódica 
mediante rituales (igualmente performativos ${ }^{9}$ ) que revitalicen su carácter sagrado:

El culto no es simplemente un sistema de signos por medio de los que la fe se traduce hacia afuera, sino el conjunto de medios gracias a los cuales se crea y recrea periódicamente. Ya consista en manipulaciones materiales o en operaciones mentales, es siempre él el que es eficaz

(FE: 389, énfasis nuestro)

La cuestión de la repetición como modo de inscripción de la creencia y de la norma ha sido abordada contemporáneamente por Judith Butler, en términos que, desde nuestra perspectiva, delimitan un nuevo ámbito de diálogo posible con problematizaciones presentes en las $F E$. Según esta autora, la sujeción al régimen de diferenciación, que conlleva cualquier formación ideológica, resulta de su reiteración periódica y ritual. La inscripción en ciertas categorías, es decir, la sujeción a la Ley, no opera mediante un acontecimiento de una vez y para siempre, como un acto original, fundante e irrepetible de inclusión en la cultura; por el contrario ésta opera a través de prácticas rituales repetidas. Ahora bien, estas (re)inscripciones periódicas resultan en instancias constitutivamente ambivalentes que pueden fracasar no sólo en la producción de la "anormalidad" (que, en definitiva, refuerza la norma), sino en tanto que reproducciones paródicas ${ }^{10}$. Según explica esta autora, "hay una risa subversiva en el efecto de pastiche de las prácticas paródicas, en que lo original, lo auténtico y lo real también están constituidos como efectos" (Butler, 1999: 186). Tomando el caso de los rituales del género, las prácticas drag resultan potencialmente subversivas, pues como imitación de ciertas posiciones de sujeto "revelan" el carácter ritual y performativo de lo que cotidianamente aparece como la ratificación de una naturalidad última (el sexo expresado genotípica y/o fenotípicamente $)^{11}$. La parodia actúa en tanto se muestra de la misma "naturaleza" que el original: como repetición que no remite a un origen que sirva de fundamento, de garantía de sutura del sentido que logre, al fin, estabilizarlo.

De un modo que entendemos conjugable con las conceptualizaciones butlerianas (resultaría redundante hablar de sus distancias), a Durkheim no se le escapa el carácter constitutivamente ambivalente de los rituales sociales, justamente, en virtud de la efervescencia colectiva, que discutimos en el primer apartado. Estas instancias eléctricas y magnéticas suelen ir acompañadas de inversiones saturnales de las normas cotidianas y de la clasificación. A partir de ello, Durkheim reconoce la ambigüedad de lo sagrado, como inscripción delirante en el logos en la que las emociones intensas invocan a transgredir los límites del orden vigente -que, por otro lado, se procura reproducir ${ }^{12}$. El modo de defender a la sociedad de esta versión híper concentrada de ella misma, es delimitar umbrales inzanjables entre el tiempo y el espacio sagrado y el de la vida cotidiana. Pero queda

\footnotetext{
${ }^{9}$ En este punto, disentimos con Ribes Leiva (2007) quien distingue entre interacciones rituales performativas, que generarían nuevos contenidos culturales y las interacciones rituales sociales, cuya función sería mantener las creencias sociales. Todo ritual es, desde nuestra perspectiva, performativo

${ }^{10}$ La posibilidad de esta subversión de sentido está asociada a que el proceso de sujeción que inaugura el mecanismo de interpelación ideológica es, siempre, también un proceso de asunción del poder, y en este sentido, de potencia. Así, la incorporación en el discurso del Otro habilita al individuo como sujeto de enunciación tanto como de enunciado, y con ello la contingencia de contestación

${ }^{11}$ La noción de parodia de Butler recupera la noción derrideana de "iterabilidad” (Derrida 1998) y sus diálogos con la teoría de "actos de habla" de John Austin. El carácter necesariamente citacional de los rituales ideológicos -esto es el hecho de que como mecanismo performativo funcionen bajo la condición de presentarse como citas que aluden a un rito original- es lo que los transforme en ámbitos siempre abiertos y fundamentalmente inestables. Con ello Derrida produce una lacerante crítica a la idea de "saturación de contexto", que según la pragmática norteamericana permitía "garantizar" el éxito de un acto de habla. La operación teórica de Butler consistirá en trasladar este carácter de los performativos a los rituales ideológicos (cuestión ciertamente habilitada por la teoría althusseriana) y pensar la posibilidad (constitutiva) de sus "fracasos" en términos de "parodia". Para un desarrollo más detallado de este argumento remitimos a Sabsay, 2005

${ }^{12}$ Por cierto, el College de Sociologie indagaría en las lógicas heterogéneas de los rituales efervescentes
} 
abierta la pregunta respecto de la efectividad que el propio Durkheim confiere a esta profilaxis.

En esta misma clave, nuestro autor, problematiza la relación entre arte y religión en las prácticas de culto, entendiendo que aunque la dimensión espectacular resulta constitutiva de éstas últimas, también supone riesgos, en tanto un juego libre de representaciones cuyas consecuencias resultan incalculables. El sentido del rito difiere del de una pura obra de arte, en tanto las representaciones que tiene por función inspirar en los fieles no son "vanas imágenes" que "a nada respondan", sin finalidad alguna, por puro gusto de combinar. Las representaciones que suscita el culto resultan necesarias para el funcionamiento de la vida moral. Durkheim es categórico: "un rito es, pues, algo diferente de un juego; forma parte de la vida seria" (FE: 356). Pero ello no obsta, insistimos, para identificar una ambigüedad que se reconoce también en cierta semejanza con las fiestas populares, cuyas manifestaciones resultan, al menos fenoménicamente las mismas: gritos, cantos, música, movimientos violentos, bailes, búsqueda de excitantes que levanten el tono vital. El peligro reside en que tanto las fiestas populares como el arte, empujan peligrosamente la frontera entre lo lícito y lo ilícito, para juguetear con ella. Pero, ¿no es este siempre el juego que habilita la efervescencia, aún la religiosa? Pareciera que Durkheim, a pesar de sus propios intentos, no logra establecer diferencias cualitativas entre ambos tipos de fenómenos, y se conforma, muy parcialmente, con diferencias de grado, de proporción entre elementos "serios" y "ligeros"13.

El movimiento conceptual de poner la "efervescencia colectiva" en el centro de la explicación sociológica como una instancia clave de producción y reproducción de la sociedad, a la vez que sugerente, resulta arriesgado. La producción de lo social quedará atravesada por cierta ambivalencia y precariedad. A diferencia de lo que ocurriría con Judith Butler, el tono durkheimiano frente a este hecho sería, según entendemos, más de consternación que de celebración.

\subsection{La ambivalencia de la comunidad mo- derna: entre el "nosotros" explosivo y el horizonte de la pluralidad}

En la puesta en valor de la efervescencia colectiva como (re)productora de la sociedad en su dimensión imaginaria (es decir, como "comunidad de creencias"), resuenan promesas cuya explosividad no debiera ser pasada por alto. Al respecto, Axel Honneth advierte:

Con este planteamiento teórico procedente de su libro sobre la religión, Durkheim se convirtió también, sin quererlo y no de un modo muy diferente que Tönnies, en el instigador de un concepto de comunidad que no mucho más tarde se vería pertrechado con la materia inflamable del resentimiento crítico-cultural (Honneth, 1999:

7).

Aún cuando esta advertencia, como veremos, debiera ser tomada en cuenta, es menester introducir algunos matices. En primer lugar, resulta oportuno recordar que uno de los "cultos" que para Durkheim debe organizar a las sociedades modernas es el del "individuo", es decir, la reformulación de una suerte de individualismo moral que se articularía en la tradición inaugurada por la Revolución Francesa (ver por ejemplo Durkheim, 1998, 2000).

Ahora bien, este culto supone algunas paradojas. Fundamentalmente: aún cuando el sujeto de esta elaboración siga siendo la colectividad, ella no re-

13 "Es ésta la razón de que la misma idea de una ceremonia religiosa de alguna importancia despierte naturalmente la idea de fiesta. Inversamente, toda fiesta, aun cuando sea originariamente puramente laica, tiene ciertas características propias de la ceremonia religiosa (...) en los dos casos se observan las mismas manifestaciones: gritos, cantos, música, movimientos violentos, bailes, búsqueda de excitantes que levanten el tono vital, etc. Con frecuencia se ha destacado que las fiestas populares llevan al exceso, hacen que se pierda de vista la frontera entre lo lícito y lo ilícito; lo mismo ocurre con las ceremonias religiosas que determinan como un deseo de violar las reglas más respetadas de ordinario. Ciertamente, no es que haya que dejar de diferenciar ambos tipos de actividad pública. El simple regocijo, el corrobori profano no tiene un objeto serio, mientras que, en su conjunto, una ceremonia ritual se dirige siempre hacia una meta grave. Con todo, hay que hacer la observación de que quizá no exista ningún regocijo que no recoja algún eco de la vida seria. En el fondo, la diferencia radica más bien en la cambiante proporción en que se combinan estos dos elementos" (FE: 356, énfasis nuestro) 
sulta ya el objeto de estas representaciones, sino de modos muy mediados ${ }^{14}$. Entendemos que este hecho representa un problema en la teoría durkheimiana, pues el valor fundamental que funciona como autoridad moral es la sociedad, como fuente de "civilización" (Durkheim, 2000). Pero, ¿puede éste subsistir sin una representación imaginaria de la totalidad, sin hipóstasis y (para usar un término caro a Cornelius Castoriadis) sin una "catectización" de "lo social" en cuanto tal? No debiéramos rehuir a tomar en cuenta que Durkheim presenta como suerte de "equivalente funcional" del tótem a la bandera, un pedazo de trapo por el cual somos capaces de dar hasta la vida (FE: 195, 207).

Entre los múltiples motivos que hacen estimulante la lectura de Durkheim poco menos de cien años después de su muerte es que tiene la valentía de no rechazar las paradojas allí donde los hechos se las imponen. Entre ellas, la curiosa condición de la modernidad, que al tiempo que promulga la "Declaración de los Derechos del Hombre" (carta magna del "culto al individuo"), produce a la nación (francesa) como "una, indivisible, centralizada" en un gran movimiento de concentración nacional (Durkheim, 1998). Sin embargo, aún habiéndose concentrado, como deja claro en las Lecciones de sociología, la razón de Estado no puede ya exigir el mismo nivel de sacrificios.

Nuevamente, entonces, nos enfrentamos al interrogante sobre el papel de la unanimidad como modo del creer en las sociedades modernas y diferenciadas ${ }^{15}$. Al respecto, en unas lecciones posteriores a $F E^{16}$, Durkheim reconoce dos formas de pro- ducción de creencias en el contexto de modernidad. Por un lado, persisten las verdades mitológicas, pero a ellas se suman, por el otro, las verdades científicas. Se trata de una distinción al nivel de los modos de producción de representaciones, antes que de sus contenidos. Así, las verdades mitológicas implican unanimidad, comunión y están vinculadas a los rituales de la efervescencia colectiva. Las verdades científicas, por el contrario, suponen la reflexividad y la especialización, un procedimiento que atienden a la pluralidad y al individualismo (en sentido moral $)^{17}$. La verdad científica impele a la duda y al cuestionamiento que la hace vivir; mientras que, por el contrario, las divergencias horadan a las verdades dogmáticas.

Ahora bien, la ciencia, diría Durkheim, sólo ha podido, en virtud de la complejidad de su objeto, producir hipótesis fragmentarias que poco han afectado la consciencia pública. Frente a ello, sigue siendo imperativo actuar, esa acción reconoce la especificidad del lenguaje moral, pero también, político. En términos de nuestro autor:

Al interior de las sociedades modernas se sostienen fórmulas que parecieran no tener un carácter religioso, pero que sin embargo tienen el carácter de dogmas que no se discuten como las nociones de democracia, de progreso, de lucha de clases, entre otras. Esta persistencia está basada fundamentalmente en la efectividad práctica de estas verdades mitológicas, ya que al expresar una concepción unánime basada en una comunión de todos los espíritus, aparecen con tal fuerza y autonomía que logran sustraerse del control

\footnotetext{
${ }^{14}$ Aquí se abren paso dos problemas teórica y políticamente relevantes. El primero, hace a la relación entre la religión laica, que parecería proponer Durkheim, y el patriotismo. Al respecto, referimos al lector al trabajo realizado por Santiago (2012) en este mismo monográfico, donde se recuperan las posiciones de Schoefflers, Wallace y Prades y el modo en que ellos polemizan. El segundo, refiere al estatuto de la "religión cívica" y el modo en que diversos análisis empíricos han tomado los "rituales cívicos" de la modernidad. Al respecto, remitimos al trabajo de síntesis y de superación de Steven Lukes (1975). Allí, el autor estadounidense analiza los emblemáticos trabajos de Shils y Young sobre la coronación de la reina Isabel, el estudio de Lloyd Warner sobre el memorial day, el trabajo de Robert Bellah sobre la religión civil de los EE.UU y el de Sydney Verba sobre la reacción popular ante el asesinato de Kennedy.

${ }^{15}$ Resulta sugerente el hecho de que, para nuestro autor, este problema se plantearía ya en las sociedades escasamente diferenciadas que se analizan en $F E$, en la relación entre las religiones tribales (más cosmopolitas) y las del clan (más "nacionales" o "particulares”). Esto podría abonar la hipótesis de Ramp (1998) y Ribes Leiva (2007), para quiénes las instancias de "unanimidad" y "diferenciación” individual terminan por ser dos dimensiones de toda sociedad.

${ }^{16}$ Nos referimos a las lecciones publicadas como Pragmatismo y sociología.

${ }^{17}$ Se repite aquí un razonamiento análogo a aquel a partir del cual nuestro autor en Lecciones de sociología había distinguido entre la consciencia colectiva difusa y la consciencia colectiva clara.
} 
y de la duda e imponerse como verdades" (FE:

Resulta interesante que los ejemplos de verdad mitológica modernas refieran a formas de concebir el orden colectivo y las fuerzas supra-individuales, hipótesis explicativa sobre las dinámicas de la sociedad a la vez que imperativos para la acción política.

Sin embargo, como hemos señalado, en nombre de estas fuerzas, y sintiéndose su depositario, los hombres no sólo son capaces de actos heroicos, sino también de la "barbarie sanguinaria" ( $F E$ : 198). El pleno de sentido puede ser terrible en sus consecuencias $^{18}$, en particular respecto de quienes quedan por fuera de la comunidad imaginaria del "nosotros". Por el contrario, el modo de producir verdad de la ciencia es constitutivamente pluralista $^{19}$, pues presupone la polifonía, la divergencia y, en definitiva, la incompletud (toda perspectiva resulta parcial respecto de la complejidad de un fenómeno).

Quedan, de este modo, planteadas las tensiones entre las representaciones colectivas que requiere el actuar en común (semejantes a las que había analizado en $F E$ ) y las que admiten divergir en una sociedad diferenciada en individuos. Ambos imperativos (la acción política y la acción individual) nos constituyen en tanto sujetos modernos, ¿Cómo zanjar este dilema?

Desde la perspectiva de Ramp (1998), es posible sostener que Durkheim desde el comienzo concibe "lo social" como inherentemente complejo. Así, la distinción entre "solidaridad mecánica" y "solidaridad orgánica", resulta no sólo del tránsito entre un estado "primitivo" a una diferenciación "moderna", sino sobre todo a una distinción entre posibilidades inherentes a toda vida social, dimensiones de la vida colectiva $^{20}$.
El lazo social, en su dimensión de "solidaridad mecánica" evocaría la nostalgia por la totalidad como origen de una unidad constitutiva trágicamente perdida en el proceso de diferenciación. Pero, como objeto de nostalgia, no resultaría previa a su difracción, sino que remitiría a la dimensión imaginaria constitutiva de la sociedad moderna.

De un modo semejante, y a contrapelo de las hipótesis de desencantamiento del mundo, para Kenneth Thompson $(1990,1998)$ las tensiones producidas por la diferenciación funcional de la modernidad estimularían las afirmaciones identitarias totales fundadas en las experiencias de lo social como fuerza "trascendente" a partir de la conformación de instancias de "comunidad simbólica". Desde su perspectiva, no resulta relevante si éstas se basan en creencias y prácticas religiosas, o si combinan discursos centrados en la nación, el grupo étnico o reivindicaciones políticas (vgr. los movimientos sociales, incluidos los de clase). Por el contrario, "comunalización" y "sacralización" debieran ser pensadas como procesos fundamentales en todas las sociedades. De este modo interpreta Thompson la reflexión durkheimiana según la cual habría algo eterno en la religión (como en la Ideología) más allá de sus modulaciones particulares: la necesidad de toda sociedad, y de todo grupo, de "mantener y reafirmar a intervalos regulares los sentimientos colectivos y las ideas colectivas que hacen que su unidad y su personalidad" (FE: 397). Asumiendo estas premisas, la sociología podría analizar las dinámicas de las relaciones de Gemeinschaft y las de Gesellschaft sin asumir su veracidad como autonarración histórica (Sasín, 2010).

\footnotetext{
18. " [en los períodos de efervescencia] se vive más intensamente y de manera muy diferente a como se hace en tiempos normales. Los cambios no son tan sólo de matiz y de grado; el hombre se convierte en otro. Las pasiones que le agitan son de una tal intensidad que no pueden satisfacerse más que por medio de actos violentos, desmesurados: actos de heró́smo sobrehumano o de barbarie sanguinaria. Es esto lo que explica, por ejemplo, las cruzadas y tantas escenas, sublimes o salvajes, de la Revolución Francesa" (FE: 198)

19. "Así, de un lado, la verdad científica no es incompatible de los grupos sociales que crecen sin cesar, imposibilita que la sociedad saque de sí misma un sentimiento único: de dónde diferentes corrientes sociales. Otra consecuencia de esta transformación, es que la tolerancia debe descansar en adelante en la idea de complejidad, de la riqueza de lo real y, por consiguiente, sobre la diversidad, a la vez necesaria y eficaz, de las opiniones" (Durkheim, 2003 [1914]: 154)

${ }^{20}$. Ribes Leiva (2007) trabaja en un sentido semejante.
} 


\section{REFLEXIONES FINALES.... A PROPÓSITO DE DURKHEIM Y EL SUR}

La denuncia directa de la noción fascista de la "comunidad del pueblo" [Volksgemeinschaft] como un señuelo engañoso que oculta la realidad de la dominación y la explotación no tiene en cuenta el hecho crucial de que esta Volksgemeinschaft se materializaba en una serie de rituales y prácticas (no sólo concentraciones y desfiles masivos, sino también campañas de gran escala para ayudar a los hambrientos, deportes organizados y actividades culturales para los trabajadores, etc.) que produjeron performativamente el efecto de Volksgemeinschaft (Žižek, 2003: 22)

Resulta relativamente claro: la Volksgemeinshaft no preexiste a su producción performativa, aunque jure y perjure ser Fundamento y Verdad de una sociedad que no deja de mostrarse deshilachada y en fuga. Con su sentencia, Žižek vuelve a enfrentamos con un problema crucial: esta instancia totalizadora de la comunidad del pueblo y su movilización política ¿resultó una excepcionalidad, el accidente monstruoso de una alteridad absoluta o, por el contrario, es una instancia irrenunciable de la acción política en contextos de modernidad? ¿Resultan estas imágenes (peligrosas, explosivas) un fundamento para la reproducción de la sociedad? Y aún más ¿es posible pensar la transformación y la acción política si se renuncia a esta instancia?

Nuevamente, resuena la preocupación de Axel Honneth respecto del combustible inflamable de la comunidad, que nos conduce a clausurar las preguntas por el "creer" y, sobre todo, a descartar la matriz del mito, el rito y la religión para pensar la acción en común. Frente a los consabidos riesgos, sería mejor renunciar a las instancias de totalización y celebrar el fin de las "grandes narraciones", entre ellas, y sobre todo, las "nacionales". Conformarse quizás con las "fallas paródicas" en los márgenes, donde "la sociedad" se muestra como puro fantasma. Pero Durkheim insiste, desde un tiempo que es y no es el nuestro:

Una sociedad no está constituida tan sólo por la masa de individuos que la componen, por el territorio que ocupan, por las cosas que utilizan, por los actos que realizan, sino, ante todo, por la idea que tiene sobre sí misma ( $F E: 397)$.
Nuestro autor nos incita: sin estas representaciones, aunque sean oscuras y fragmentarias, no es posible salir del titubeo, no es posible ni ser ni actuar en común. Nos permitirnos una última duda respecto de los diagnósticos que definieron la "posmodernidad" como crisis de las instancias totalizadoras de sentido. Podría muy bien argumentarse que "el Mercado", como fundamento y razón de la organización política, cumplió un rol de sutura, como una metáfora singular a partir de la que la sociedad se pensó ella misma. La consolidación de ésta como sentido común estuvo estrechamente vinculada a la generalización de ciertos rituales y, en particular, a la conversión de lenguajes que otrora habían articulado representaciones imaginarias alrededor de la "ciudadanía" en repertorios que valoraban otros modos de ser hombres y mujeres, singularmente el de "consumidor/a". Saldar las deudas con la última duda, entonces, sospechar del anunciadísimo desencantamiento posmoderno del mundo, para preguntarnos por los idola a los que habremos dado albergue.

Pero luego, salir de la duda, actuar. Ahora bien, ¿qué ritos y mitos cabe colocar actualmente en el lugar que, en la enunciación durkheimiana, ocupaban el progreso, la lucha de clases o la democracia (FE: 184)? Algunas experiencias de la última década iluminan, desde el Sur, la emergencia de mitos que intentan, precaria y momentáneamente, performar (¿de nuevos modos?) la inasible totalidad social. En algunos casos, emergen "nuevas" representaciones colectivas, o mejor, representaciones que articulan de un modo singular "lo tradicional" y "lo innovador" (vgr. el poderoso y sugerente oxímoron de un estado plurinacional). Tal es el caso de las representaciones construidas alrededor de la figura de los "pueblos originarios", que no se contentan con ser una más entre las identidades de los márgenes, sino que se formula (y se performa) como "fundamento". Pero también es el caso, de aquellas representaciones que recuperan "tradiciones" más próximas y modernas (la bolivariana, y aún más cerca, la de los años setenta), revivificadas y rescritas con nuevos trazos. En estas reescrituras (plenas de rituales y de conmemoraciones que, en realidad, inauguran nuevas génesis) se observa la resignificación de valores que una parte de la buena sociología posmoderna había dado por muertos: "nación", "desarrollo", "trabajo" e incluso "justicia social". 
De este modo, asistimos (entusiasmados o consternados, poco importa) a la producción de remozados y polifónicos panteones que entrecruzan espacios imaginarios que en otros tiempos resultaban heterogéneos ¿Cómo sería el estudio que diera cuenta de la "coronación ${ }^{21}$ " de Evo Morales en las ruinas de Tihuanco, pero a la vez, en el Parlamento Nacional? Rituales que, se contentaría Lukes (1975), no dejan de subrayar las marcas de la subordinación social, pero esta vez impugnándolas desde el poder.

Aunque suene gastado, las reflexiones enunciadas (y las apenas sugeridas) en $F E$ nos ofrecen herramientas para pensar nuestro tiempo. Al respecto, el Sur ilumina con la luz de la excepción (que, como sabemos desde Althusser, es siempre la regla): Aquí los (nuevos y algunos viejos) dioses gozan de muy buena salud.

\section{BIBLIOGRAFÍA}

Alexander, J. (2011): Performance and Power. Cambridge: Polity Press.

Althusser, L. (1988): Ideología y aparatos ideológicos del estado. Buenos Aires: Nueva Visión.

ButLer, J. (1993): Bodies That Matter: On the Discursive Limits of "Sex", New York \& London: Routledge.

ButLer, J. (1997): Mecanismos psíquicos del poder. Madrid: Ediciones Cátedra.

ButLer, J. (1999): El género en disputa. Barcelona: Paidós.

De Marinis, P. (2010): "Comunidad: derivas de un concepto a través de la historia de la teoría sociológica". Papeles del CEIC, Vol. 1, marzo-sin mes, Universidad del País Vasco/Euskal Herriko Unibertsitatea España, pp. 1-13.

DERRIDA, J. (1998): Márgenes de la filosofia. Madrid: Cátedra.

Durkheim , E (1967) [1893]: De la división del trabajo social. Buenos Aires: Editorial Schapire.

Durkheim, E. 1998 [1898]: "El individualismo y los intelectuales", en Lecciones de sociología. Física de las costumbres y del Derecho y otros escritos sobre el individualismo, los intelectuales y la democracia. Madrid: Miño y Dávla, pp. 285-300.

DuRKheim, E (2000) [1906]: “La determinación del hecho moral”, en Sociología y filosofía Madrid: Miño y Dávla, pp, 59-86.

DuRKHEIM, E (2007) [1912]: Las formas elementales de la vida religiosa, Madrid: Akal.

DURKHEIM, E 1965 [1895]: Las reglas del método sociológico. Buenos Aires: Editorial Schapire.

DuRKheIM, E (2001) [1914]: "Le dualisme de la nature humaine et ses conditions sociales", en Scientia, XV, 1914, pp. 206-221. Disponible en http://classiques.uqac.ca/classiques/Durkheim_emile/sc_soc_et_action/texte_4_15/ dualisme_nature_hum.doc

Durkheim, E (2003) [1914]: Pragmatismo y sociología. Buenos Aires. Montressor.

Durkheim, E (1999) “Comunidad: Esbozo de una historia conceptual”, Isegoría: Revista de filosofía moral y política, 20, pp. 5-15.

Jones, A. (2005): "Practices and presuppositions: some questions about Durkheim and Les Formes elementaires de la vie religieuse", en ALEXANDER, J. SMITH, P. The cambridge companion to Durkheim. Cambridge: Cambridge University Press, pp. 80-100.

LACAN, J. (2003): "El estadio del espejo como formador de la función del yo (je) tal como se nos revela en la experiencia psicoanalítica", en ZIZEK, S, Ideología: un mapa de la cuestión. México: FCE, pp. 107 a 114.

LACLAU, E. (1996): Emancipación y diferencia. Buenos Aires: Ariel.

LaClau, E. y MOUFFE, C. (1987): Hegemonía y Estrategia Socialista. Hacia una radicalización de la Democracia., Madrid: Siglo XXI.

LuKES, S. (1975): "Political Ritual and Social Integration”, en Sociology May, 9. Oxford: Balliol College. pp. 289-308.

LuKes, S. (1984): Emile Durkheim: su vida y su obra. Madrid: Alianza.

Nocera, P. (2009): "Los usos del concepto de efervescencia y la dinámica de las representaciones colectivas en la sociología durkheimiana," en Revista Española de Investigaciones Sociológicas (Reis) N. ${ }^{\circ}$ 127, Madrid. pp. 93-11.

\footnotetext{
${ }^{21}$. Usamos este término en relación al clásico estudio de Edward Shils y Michael Young, en el que hicieron uso de categorías de FE para dar cuenta de la coronación de la reina Isabel II de Inglaterra.
} 
Paoletti, G. (1998): “The cult of images", en ALLEN, N. J. (ed), On Durkheim's Elementary life of religious forms. London: Routledge, pp. 78 -91.

Ramos Torre, R. (2007) "Estudio preliminar", en Las formas elementales de la vida_religiosa Madrid: Akal, pp. I-XXVI.

Ramos Torre, R, (2010): “La comunidad moral en la obra de Emile Durkheim”, en de MARINIS, P., GATTI, G. y IRAZUZTA,I (eds.), La comunidad como pretexto. En torno al (re)surgimiento de las solidaridades comunitarias. Barcelona: Anthropos, pp: 383-412.

RAMP, W (1998): "Effervescence, differentiation and representation in the elementary forms", en ALLEN, N. J. (ed), On Durkheim's Elementary life of religious forms. London: Routledge, pp. 136- 148.

Rawls, A. (2001): "Durkheim's Treatment of Practice", en Journal of Classical Sociology March, vol. 1 no. 1. SAGE Publications Los Angeles, London, New Delhi and Singapor, pp. 33-68.

Ribes Leiva, A. (2007): “Durkheim contra Durkheim: los límites de la lógica. secuencial totalidad-fragmentación”, en Nómadas. Revista Crítica de Ciencias Sociales y Jurídicas | 28 (2010.4). Disponible en: http://www.ucm.es/info/ nomadas/28/albertojribes.pdf

Santiago, J. (2012): "El nacionalismo y las formas elementales de la vida religiosa”, Política y Sociedad.

SABSAY, L. (2005). Política de lo transformativo: lenguaje, teoría de la deconstrucción antiesencialista y subjetividad. Obtenido de www.iigg. fsoc.uba.ar/3jornadas/jovenes/templates/eje\%/sabsay

SASín, M. (2010) "La comunidad estéril. El recurso comunitario como forma de la autodescripción social”, en Papeles del CEIC, Vol. 1, marzo-sin mes, Universidad del País Vasco/Euskal Herriko Unibertsitatea España. pp. 1-35

SAZBÓN, D. B. (2003) “Articulaciones entre ciencia y política. La reflexión sociológica francesa a fines del XIX: Durkheim y Sorel”. Tesis de Maestría. Buenos Aires: FLACSO.

Stedman Jones, S. (2006): “Action and the Question of the Categories: A Critique of Rawls” Durkheimian Studies 12. UK: Berghahn Journals pp. 37-67.

Stedman Jones. S. (1998): “The concept of belief in The elementary forms",en ALLEN, N. J. (ed), On Durkheim's Elementary life of religious forms. London: Routledge, pp. 53-65.

Thompson, K (1998) "Durkheim and sacred identity “, en ALLEN, N. J. (ed), On Durkheim's Elementary life of religious forms. London: Routledge pp 92-104.

Thompson, K. (1990): "Secularization and sacralization” en ALEXANDER, J. y SZTOMPKA, P. ( 1990) Rethinking progress movements, forces, and ideas at the end of the 20th century .Unwin Hymab: Boston, pp 161-181.

ŽIŽEK, S (2003): “Introducción”, en Ideología: un mapa de la cuestión. México: FCE, pp. 7- 42. 